\title{
“ASILO” E “O GRANDE URSO": A GUERRA FRIA NAS HISTÓRIAS EM QUADRINHOS DO CAPITÃO AMÉRICA (1989)
}

Leonardo Brandão ${ }^{1}$

\begin{abstract}
Resumo: A URSS, fruto dos desdobramentos da Revolução Russa de 1917, foi alvo, ao longo dos anos da Guerra Fria, de uma ampla gama de representações na cultura de massas norteamericana, como filmes, propagandas, reportagens em revistas, HQs etc. Diante desse quadro, foi realizado uma pesquisa com as HQs (Histórias em Quadrinhos). O objeto de análise foi uma aventura do Capitão América com o grupo Super Soldados Soviéticos (Soviet Super Soldiers) da Marvel. A aventura analisada divide-se nas histórias "Asilo" e "O Grande Urso", ambas originalmente publicadas no ano de 1989 na HQ de título "Capitão América". O objetivo foi compreender tais aventuras no contexto que engloba os estertores da Guerra Fria, percebendo as representações construídas sobre esse grupo e sobre a URSS, além da relação entre os integrantes dos Super Soldados Soviéticos com o Capitão América. A conclusão é de que a URSS foi representada nesta HQ como um país sem liberdade e que perseguia até mesmo seus próprios super-heróis.
\end{abstract}

Palavras-chave: Histórias em Quadrinhos; Guerra Fria; URSS; Socialismo.

\section{"ASYLUM" AND "THE GREAT BEAR": THE COLD WAR IN THE COMICS OF CAPTAIN AMERICA (1989)}

\begin{abstract}
The USSR, as a result of the developments of the Russian Revolution of 1917, was a target, throughout the Cold War years, of a wide range of representations in American mass culture, such as films, advertisements, magazine articles, comic books, etc. In view of this, a research was carried out with comics. The object of analysis was an adventure of Captain America with the group of Soviet Super Soldiers of Marvel. The adventure analyzed is divided in the stories "Asilo" and "The Great Bear", both originally published in the year of 1989 in the titled "Captain America". The objective was to understand such adventures in the context that encompasses the Cold War rattles, perceiving the representations built on this group and on the USSR, as well as the relationship between the members of the Soviet Super Soldiers and Captain America. The conclusion is that the USSR was represented in this comic as a country without freedom and that he pursued even his own superheroes.
\end{abstract}

Keyword: Comics; Cold War; USSR; Socialism.

\section{"ASILO" Y "EL GRAN URSO": LA GUERRA FRÍA EN LAS HISTORIAS EN CUADRINOS DEL CAPITÁN AMÉRICA (1989)}

Resumen: La URSS, fruto de los desdoblamientos de la Revolución Russa de 1917, fue objeto, a lo largo de los años de la Guerra Fría, de una amplia gama de representaciones en la cultura de masas norteamericana, como películas, propagandas, reportajes en revistas, HQs

\footnotetext{
1 Doutor em História pela PUC/SP. Professor do Departamento de História e Geografia da Universidade Regional de Blumenau - FURB. Docente do Programa de Pós-Graduação em Desenvolvimento Regional da FURB. Coordenador do Laboratório de Estudos Contemporâneos (LEC).
} 
etc. Ante ese cuadro, se realizó una investigación con las HQ (Historietas). El objeto de análisis fue una aventura del Capitán América con el grupo de Super Soldados Soviéticos (Soviet Super Soldiers) de Marvel. La aventura analizada se divide en las historias "Asilo" y "El Gran Urso", ambas originalmente publicadas en el año 1989 en la HQ de título "Capitán América". El objetivo fue comprender tales aventuras en el contexto que engloba a los estertores de la Guerra Fría, percibiendo las representaciones construidas sobre ese grupo y sobre la URSS, además de la relación entre los integrantes de los Super Soldados Soviéticos con el Capitán América. La conclusión es que la URSS fue representada en esta HQ como un país sin libertad y que perseguía incluso a sus propios super héroes.

Palabras claves: Historietas; Guerra Fría; URSS; Socialismo.

\section{INTRODUÇÃO}

A Guerra Fria moldou o mundo contemporâneo por mais de 40 anos. Ela constitui, nas palavras do historiador Paulo Fagundes Vizentini, "um dos fenômenos mais importantes e polêmicos da História Contemporânea, marcado que foi, e ainda é, pelo confronto ideológico do século" (2005, p. 197). De fato, como assegura o historiador Eric Hobsbawm, a Guerra Fria moveu-se no plano ideológico, mas embora ambos os governos demonizassem seu antagonista, a presença do anticomunismo nos Estados Unidos da América (EUA) era muito maior do que a presença do antiamericanismo na União das Repúblicas Socialistas Soviéticas (URSS), e isso porque os EUA representavam uma democracia que precisava eleger seus dirigentes (ganhar votos no Congresso ou em eleições presidenciais e parlamentares), e nada melhor para isso do que a criação de um clima de perigo externo constante. Portanto, havia um potencial político na denúncia do inimigo (HOBSBAWM, 1995, p. 232).

Embora a Guerra Fria apresente um cunho eminentemente ideológico, a maior parte da produção historiográfica sobre ela ainda se encontra no campo da História Diplomática ou Internacional, localizando os acordos, os tratados, os conflitos etc. Por outro lado, muitos especialistas sobre esse assunto vêm defendendo, nos últimos anos, que as investigações sobre a Guerra Fria também poderiam ser enriquecidas a partir dos estudos na esfera na propaganda e da produção cultural, e isso a partir de fontes ainda pouco exploradas, como a literatura, o cinema, os jogos eletrônicos e as histórias em quadrinhos (VALIM, 2015, p. 180). Para as historiadoras Laura Vazquez e Conceição Pires, por exemplo, as HQs formam uma parte importante dessa cultura de massa, junto com o cinema e o jornal, sendo que elas "exerceram e exercem significativa influência comportamental nos seus leitores e se mostraram como meio inovador de comunicação" (2017, p. 158). 
De fato, no universo das Histórias em Quadrinhas, o contexto da Guerra Fria marcou um período inovador no qual muitos super-heróis foram criados e no qual as HQs se consolidaram como um entretenimento juvenil, chegando mesmo "a competir com a televisão pelo tempo de lazer dos leitores” (HARUMI, 2016, p. 27). Além disso, foi nessa época também que entrou em ação a dupla Jack Kirby e Stan Lee, responsáveis por uma renovação bastante significativa neste universo. No livro "Marvel Comics: a história secreta", o escritor Sean Howe relata que parte do sucesso dessa editora ${ }^{2}$ deveu-se aos heróis inventados nesse contexto histórico. Na década de 1960, por exemplo, e isso em questão de poucos meses ${ }^{3}$, a editora Marvel introduziu nas HQs um personagem que "a radiação metamorfoseia em uma besta verde e violenta, um médico aleijado que vira Deus do Trovão, um armamentista com problemas cardíacos que constrói uma armadura de metal para enfrentar comunistas" (HOWE, 2013, p. 11).

Sem dúvida, a bipolarização (EUA x URSS) forneceu inúmeros elementos para a criação de super-heróis, histórias e narrativas, muitas vezes, carregadas de ampla carga ideológica. Para o historiador Maurício Parada, esse período gerou um imaginário social popular riquíssimo, sendo que "filmes sobre a catástrofe do aniquilamento humano, literatura de espionagem e super-heróis salvadores da humanidade foram produzidos em escala maciça pela indústria cultural" (PARADA, 2014, p. 153).

Assim, para além das esferas militar - como as guerras, por exemplo, localizadas no Vietnã e na Coreia - e diplomática - como na questão dos mísseis de Cuba - a Guerra Fria também foi disputada com ações no âmbito da cultura de massas. Como já afirmamos, a retórica da Guerra Fria influenciou a criação de personagens que iriam povoar o universo dos quadrinhos.

\footnotetext{
${ }^{2}$ As duas principais editoras de quadrinhos que tiveram sua origem nos Estados Unidos são a $D C$ Comics e a Marvel Comics, sendo ambas criadas no final da década de 1930. A DC (abreviatura de Detective Comics) surgiu em 1938 com o lançamento da primeira HQ do Superman (no ano seguinte, a editora apresentaria o Batman, com arte de Bob Kane e texto de Bill Finger). A editora Marvel teve sua primeira publicação em 1939 (inicialmente chamada de Timely Comics, mas já em sua segunda edição o nome fora mudado para Marvel Mystery Comics). Ambas as editoras, existentes até os dias atuais, competem entre si pelo público consumidor de quadrinhos, tanto nos Estados Unidos quanto no Brasil (HARUMI, 2016)

${ }^{3}$ A questão da radiação, por exemplo, bastante presente no imaginário norte-americano da época, teve um papel de destaque na criação de diversos personagens, como o Quarteto Fantástico (1961), expostos à radiação cósmica; Homem-Aranha (1962), que obteve seus poderes ao ser picado por uma aranha radioativa; e mesmo o Incrível Hulk (1962), exposto acidentalmente à radiação gama. Como lembra o historiador Thiago Monteiro Bernardo, muitos desses personagens "eram capazes tanto de proteger a nação quanto de fabricar e atualizar os armamentos nucleares, um dos principais pontos da campanha de John Kennedy para a presidência em 1960" (BERNARDO, 2015, p. 117).
} 
Neste artigo, tomamos a Guerra Fria como o contexto explicativo para a análise ${ }^{4}$ de uma aventura do Capitão América com o grupo "Super Soldados Soviéticos" (Soviet Super Soldiers). Este grupo foi criado em 1981 pelo roteirista Bill Mantlo e desenhado inicialmente por Sal Buscema, ambos pertencentes a Marvel Studios. O grupo apareceu pela primeira vez dentro de uma história publicada na revista The Incredible Hulk ${ }^{5}$, edição 258, lançada nos EUA em abril de 1981.

Importante informar que, no Brasil, este grupo nunca obteve uma HQ apenas sua, aparecendo apenas de modo coadjuvante em histórias de personagens famosos da editora, como Hulk, Capitão América ou X-Men ${ }^{6}$. Nos EUA, essa equipe chegou a ganhar uma HQ apenas para si em novembro de 1992, intitulada Soviet Super Soldiers, mas com a Guerra Fria já finalizada, a edição não obteve sucesso e foi cancelada, não passando desta edição inicial ${ }^{7}$.

A aventura analisada neste artigo encontra-se dividida em duas partes. Ela foi originalmente publicada em 1989 nos EUA (já nos estertores da Guerra Fria), mas foi traduzida e publicada no Brasil somente no ano de 1992, na edição de número 163 da HQ do Capitão América ${ }^{8}$. Nela, veremos primeiramente os integrantes do grupo "Super Soldados Soviéticos" fugindo da URSS para pedir asilo ao Capitão América nos EUA. Em seguida, após uma série de eventos, é o próprio Capitão América quem acaba indo até a URSS e acaba entrando em combate em território comunista. Entretanto, antes de avançarmos para a história em si, cabe realizarmos uma apresentação mais consistente de quem eram os personagens que compunham a equipe chamada: Super Soldados Soviéticos.

\footnotetext{
${ }^{4}$ A análise das histórias em quadrinhos, como explica o sociólogo Nildo Viana, pode ser realizada sob várias formas. Não há um método correto ou imprescindível a ser utilizado, pois isso depende da abordagem teórica, da opção metodológica, dos objetivos propostos e mesmo da formação do analista (VIANA, 2016, p. 47). Neste artigo, a ação de pesquisa empreendida localiza-se na dimensão da História Cultural, mobilizando a noção de representação como eixo central de análise.

${ }^{5}$ No Brasil, essa edição foi traduzida e publicada três anos depois, no ano de 1984, na edição de número 13 da revista do Incrível Hulk.

${ }^{6}$ Esse grupo de super-heróis não chegou a ter um título apenas seu no Brasil, mas apareceu, além da HQ do Capitão América analisada neste artigo, nas seguintes publicações: Heróis da TV, n. 20, de 1981; O Incrível Hulk, n. 13, de 1984; O Incrível Hulk, n. 14, de 1984; Heróis da TV, n. 108, de 1988; Torneio de Campeões, n. 1,2 e 3, de 1988; X-Men, n. 4, de 1989; e Superalmanaque Marvel, n. 1, de 1989.

${ }^{7}$ Vale lembrar que essa edição também nunca chegou a ser traduzida e nem publicada no Brasil.

${ }^{8}$ Além disso, cabe destacar que essa edição em português condensou em uma só revista duas histórias, que foram publicadas originalmente nas edições de número 352 e 353 de Captain America, respectivamente, as edições de abril e maio de 1989.
} 


\section{OS PERSONAGENS QUE INTEGRAM O SUPER-SOLDADOS SOVIÉTICOS}

No universo das histórias em quadrinhos da Marvel, os Super Soldados Soviéticos formam um grupo de seres superpoderosos que uniram forças a pedido do governo soviético. Seu líder era chamado Vanguard, um personagem armado com a foice numa mão e o martelo na outra, ou seja, os dois principais símbolos da URSS. A primeira aparição deste personagem foi numa revista do Homem de Ferro, número 109, publicada nos Estados Unidos em abril de 1978. Esta revista não chegou a ser publicada no Brasil.

A história de Vanguard tem início na Rússia Soviética. Ele teria nascido em Minsk, filho de um físico nuclear russo chamado Sergei Krylov e irmão gêmeo de Laynia Sergeievna Petrovna (a personagem "Estrela Negra”). Ambos teriam nascidos mutantes (seres dotados de habilidades sobre-humanas) e foram treinados como agentes especiais. Quando adulto, Vanguard (cujo verdadeiro nome era Nikolai Krylenko), juntou-se a KGB e, junto a sua irmã, teria sido recrutado pelo governo socialista para formar o grupo dos "Super Soldados Soviéticos".

Os poderes mutantes de Vanguard eram ampliados pelo uso da foice e do martelo, dois instrumentos construídos com tecnologia avançada do governo soviético e fornecidos ao herói. Através desses objetos ele conseguia gerar campos de força, repelir, absorver ou reorientar várias espécies de energia em formas de explosões. Uma vez arremessados, a foice e o martelo também retornavam as suas mãos ${ }^{9}$.

Outro importante personagem que integrou o grupo dos Super Soldados Soviéticos foi Mikhail Uriokovitch Ursus, sendo chamado na equipe pelo nome de "Ursa Maior". Ele apresentava o poder de se transformar num gigantesco urso marrom - animal que é um dos símbolos mais conhecidos da URSS - adquirindo enorme força, mas preservando sua inteligência humana, inclusive com a capacidade de falar.

Os poderes de Mikhail Ursus se manifestaram pela primeira vez quando, acidentalmente, ele caiu nos Montes Urais. Mas sua habilidade de transformar-se num urso lhe permitiu sobreviver e se integrar com os animais da floresta. Anos mais tarde, Mikhail Ursus foi recrutado pelo governo soviético, ao lado dos gêmeos Estrela Negra e Vanguard, para formar a equipe dos Super Soldados Soviéticos ${ }^{10}$.

\footnotetext{
${ }^{9}$ http://www.marvel-world.com/encyclopedie-1292-fiche-vanguard-biographie.html, acesso: em 28/04/2018.

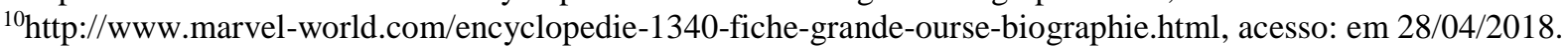




\section{PRIMEIRA PARTE: ASILO}

Esta primeira parte da história, intitulada "Asilo"", tem início com uma página inteira do Porto de Nova Iorque, com destaque para a Estátua da Liberdade. Próxima a ela, encontrase a "Ilha dos Vingadores", descrita como sendo um "quartel-general flutuante da mais poderosa equipe de superseres do mundo livre". Notamos, já neste momento inicial, que a utilização do termo "mundo livre" numa página inteira que traz a figura emblemática da Estátua da Liberdade contém elementos discursivos suficientes para caracterizar os EUA como a Pátria da Liberdade, e isso em oposição ao mundo não-livre, que seria os países da URSS, do Leste Europeu ou as demais nações que não eram compreendidas como parte do mundo livre, como China e Cuba.

Logo em seguida nesta HQ, observamos um grupo de novatos super-seres sendo testados pelo Capitão América. O objetivo era ver qual deles teria condições de disputar uma vaga para ser membro dos Vingadores. No entanto, quando o treinamento está prestes a acabar, o Capitão América recebe um chamado do Complexo de Segurança e se ausenta por alguns instantes do local de treinamento. E é justamente neste momento que chegam os Super Soldados Soviéticos (que serão a partir daqui chamados apenas de SSS). Eles chegam numa espécie de teletransporte efetuado por sua integrante feminina, chamada Estrela Negra, tal como podemos observar na imagem a seguir:

Figura 1 - Cena da HQ em que aparece a chegada dos Super Soldados Soviéticos em Nova Iorque

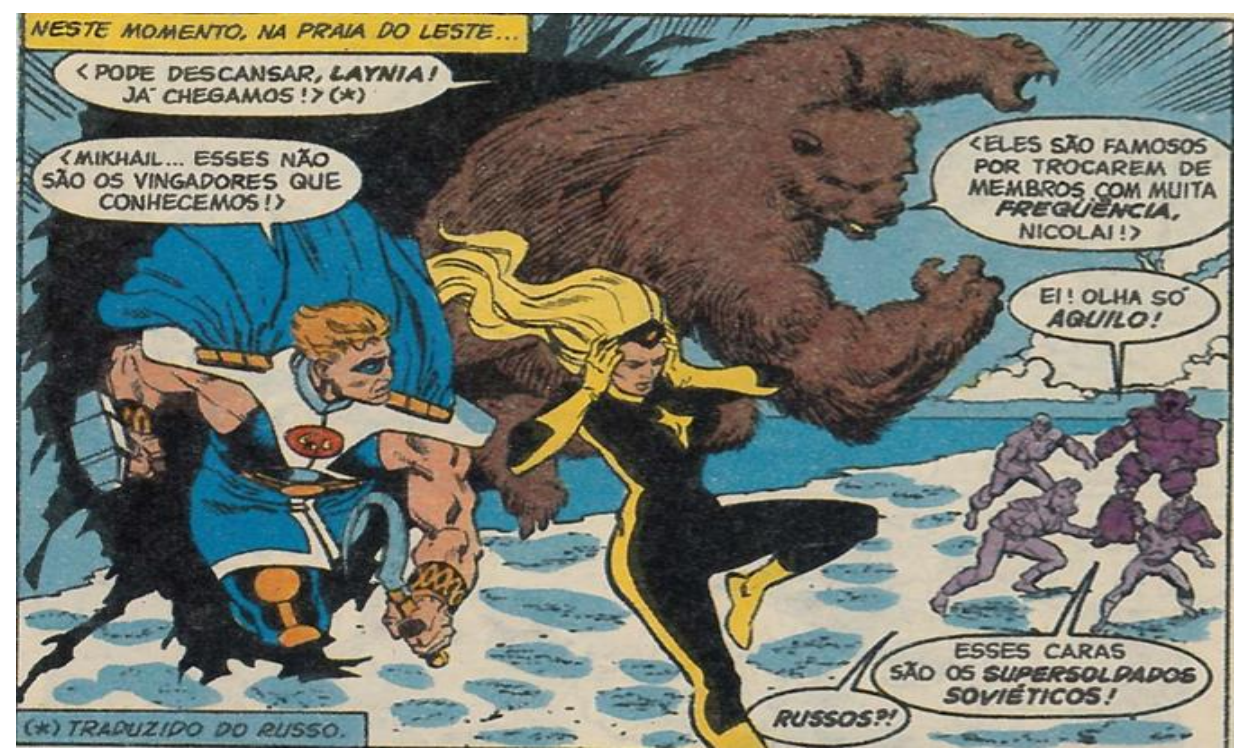

\footnotetext{
${ }^{11}$ Ao total, são 44 páginas de quadrinhos, todos coloridos, desenhados por Kieron Dwyer, roteirizado por Mark Gruenwald e com a arte final de Al Milgrom. A parte "Asilo" contém 22 páginas e "O Grande Urso" também 22 páginas.
} 
Tão logo os SSS chegam, ocorre a confusão. Na ausência do Capitão América, eles são confundidos pelos heróis novatos com invasores, e assim eles começam a travar uma batalha contra os russos. Na cena inicial do combate, reproduzida a seguir, percebemos elementos que já nos remetem ao clima da Guerra Fria:

Figura 2 - Combate entre os Super Solados Soviéticos e os heróis que faziam o teste para entrar para a equipe dos Vingadores

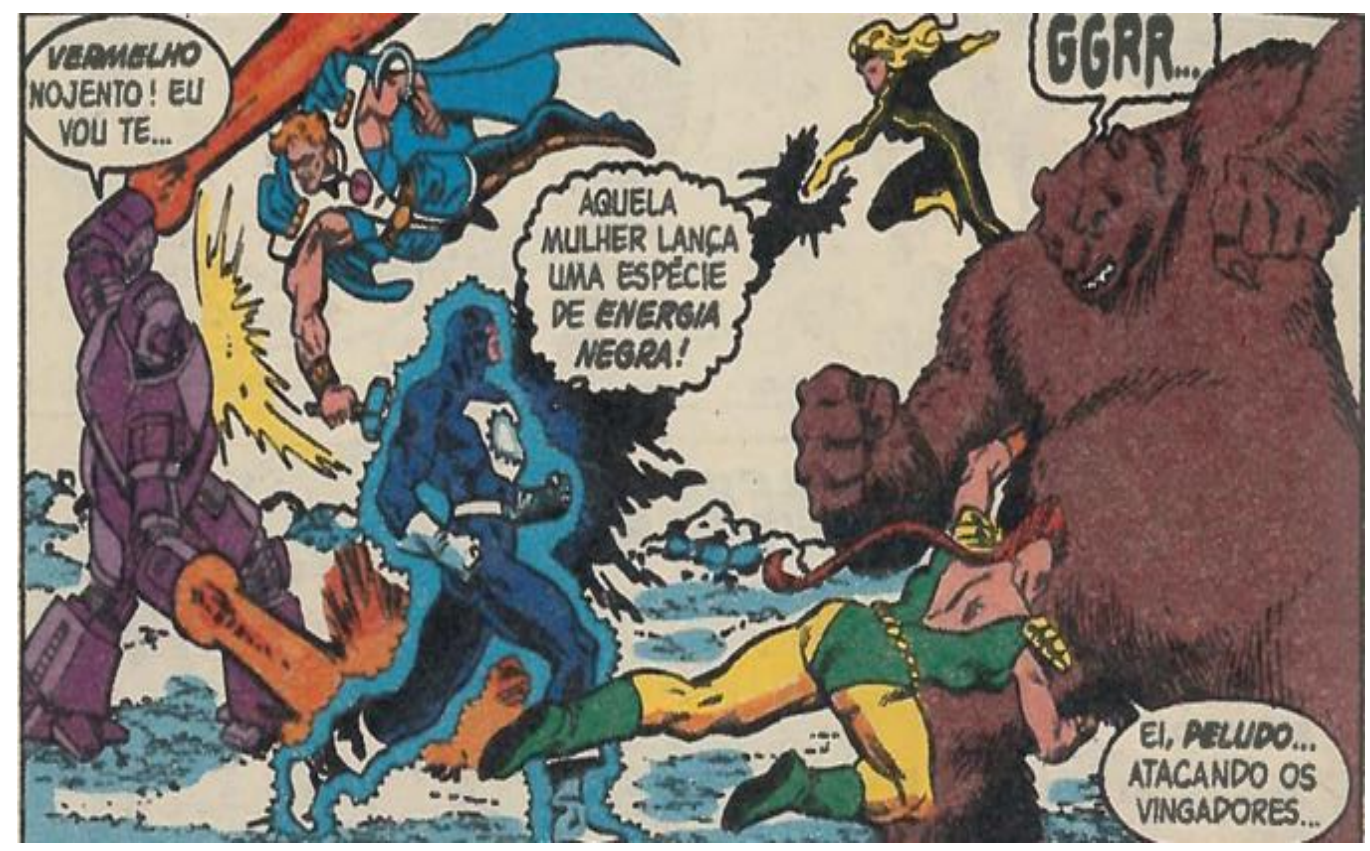

Na cena que demonstra a luta, vemos num balão escrito: "Vermelho Nojento! Eu vou te...", proferido por um dos personagens a Vanguard. Pontuamos que o termo "vermelho nojento!" só poderia ser dito num clima onde o imaginário social a respeito do socialismo justificasse tal xingamento, sendo essa HQ, portanto, mais um componente que ajudaria a estabelecer esse imaginário.

Com o combate em andamento e a equipe dos novatos sendo derrotada pelos SSS, eis que retorna o Capitão América e a confusão tem seu término. O líder dos SSS, Vanguard, explica ao Capitão que eles vieram aos EUA em paz e em busca de "asilo em seu país". A seguir a reprodução do momento em que o pedido de "asilo político" é explicado ao Capitão América: 
Fronteiras: Revista de História

"Asilo" e "O Grande Urso": a Guerra Fria nas Histórias em Quadrinhos do Capitão América (1989) Leonardo Brandão

Figura 3 - Os Super Soldados Soviéticos explicam o pedido de asilo político nos EUA

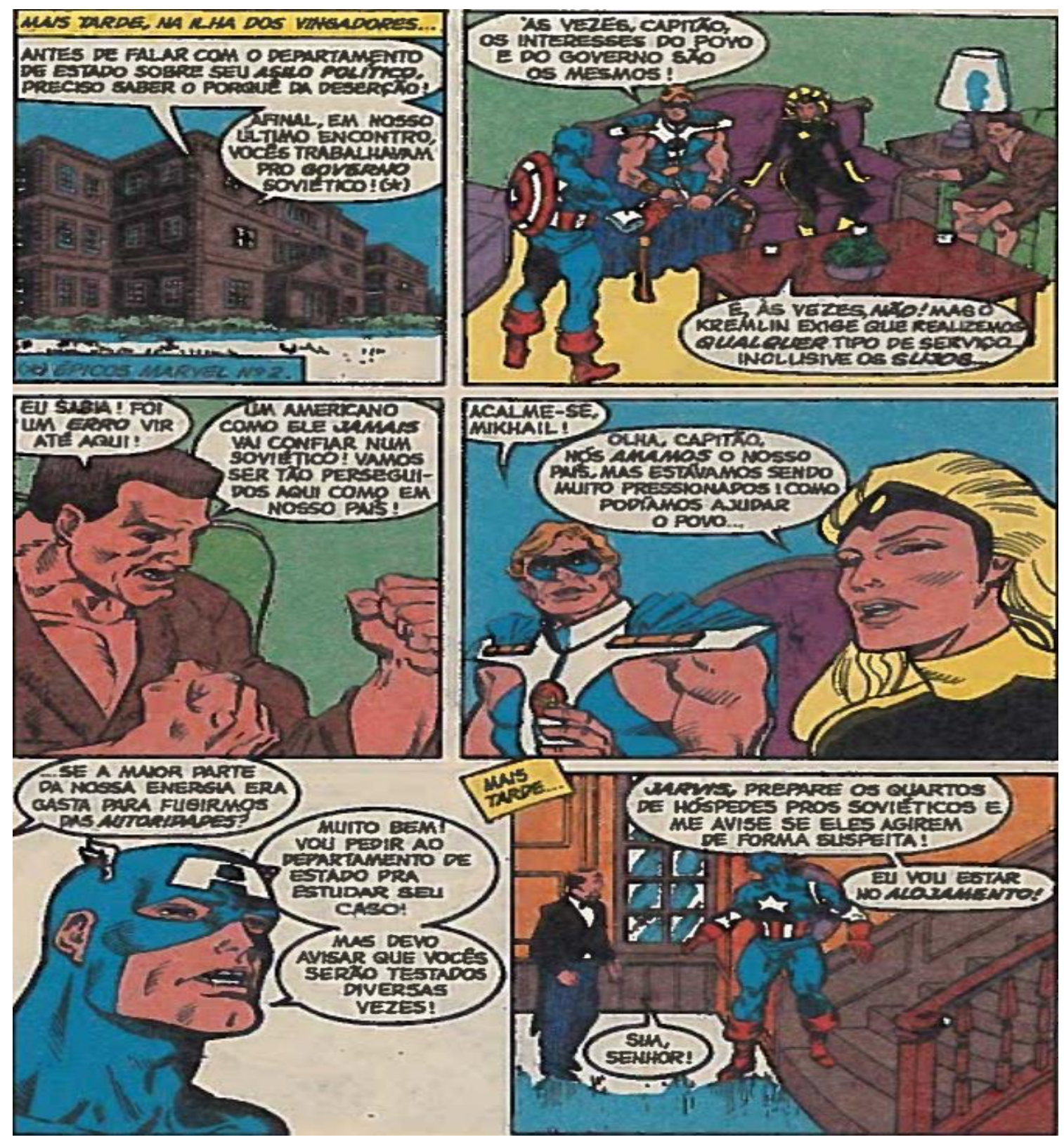

O fato dos integrantes do grupo dos Super Soldados Soviéticos fugirem para os EUA para procurar "asilo político" demonstra claramente a forma predominante de representação acerca da URSS: uma terra que contém um governo totalitário. Como forma de corroborar com o que estamos afirmando, a personagem Estrela Negra profere as seguintes palavras ao Capitão América: “Às vezes, Capitão, os interesses do povo e do governo são os mesmos! E, às vezes, não! Mas o Kremlin exige que realizemos qualquer tipo de serviço...inclusive os sujos". Evidentemente, esta cena demonstra a URSS como um lugar onde opositores ao governo podem ser perseguidos, silenciados ou até mesmo mortos, aspecto esse que seria bem 
diferente da realidade existente no país do Capitão América, onde as liberdades democráticas estariam, em tese, asseguradas. Ainda assim, o clima de desconfiança mútua, típico da Guerra Fria, é trazido à tona pela fala do russo Mikhail Ursus: "Eu sabia! Foi um erro vir até aqui! Um americano como ele jamais vai confiar num soviético! Vamos ser tão perseguidos aqui como em nosso país". Além disso, Estrela Negra complementa seu argumento, e diz ao Capitão América: “Olha, Capitão, nós amamos o nosso país, mas estávamos sendo muito pressionados! Como podíamos ajudar o povo se a maior parte da nossa energia era gasta para fugirmos das autoridades?". Assim, por meio dessa fala, fica caracterizado que o problema da URSS não é o seu povo, mas sim seus governantes autoritários.

Ao compreender o motivo do pedido de asilo, o Capitão América acolhe os heróis fugitivos e destina a eles um alojamento na sede dos Vingadores. Neste ínterim, o próprio Capitão acaba sendo chamado pela Central de Comunicação para investigar um outro acidente. Assim, enquanto o Capitão América encontra-se mais uma vez em missão de investigação, os integrantes dos SSS relaxam - ou tentam relaxar - no seu aposento. Neste momento, ocorre uma cena em que temos uma série de elementos emblemáticos das tensões decorrentes do período da Guerra Fria.

$\mathrm{Na}$ imagem a seguir, enquanto a personagem Estrela Negra aparece deitada na cama entretendo-se com uma revista em mãos (de título "Glamour”), Mikhail Ursus e Vanguard aparecem assistindo imagens de televisão. Mas eis que na tela aparece a figura do presidente dos Estados Unidos na época, Ronald Reagan. 
Figura 4 - Os Super Soldados Soviéticos deparam-se com o ex-presidente Ronald Reagan

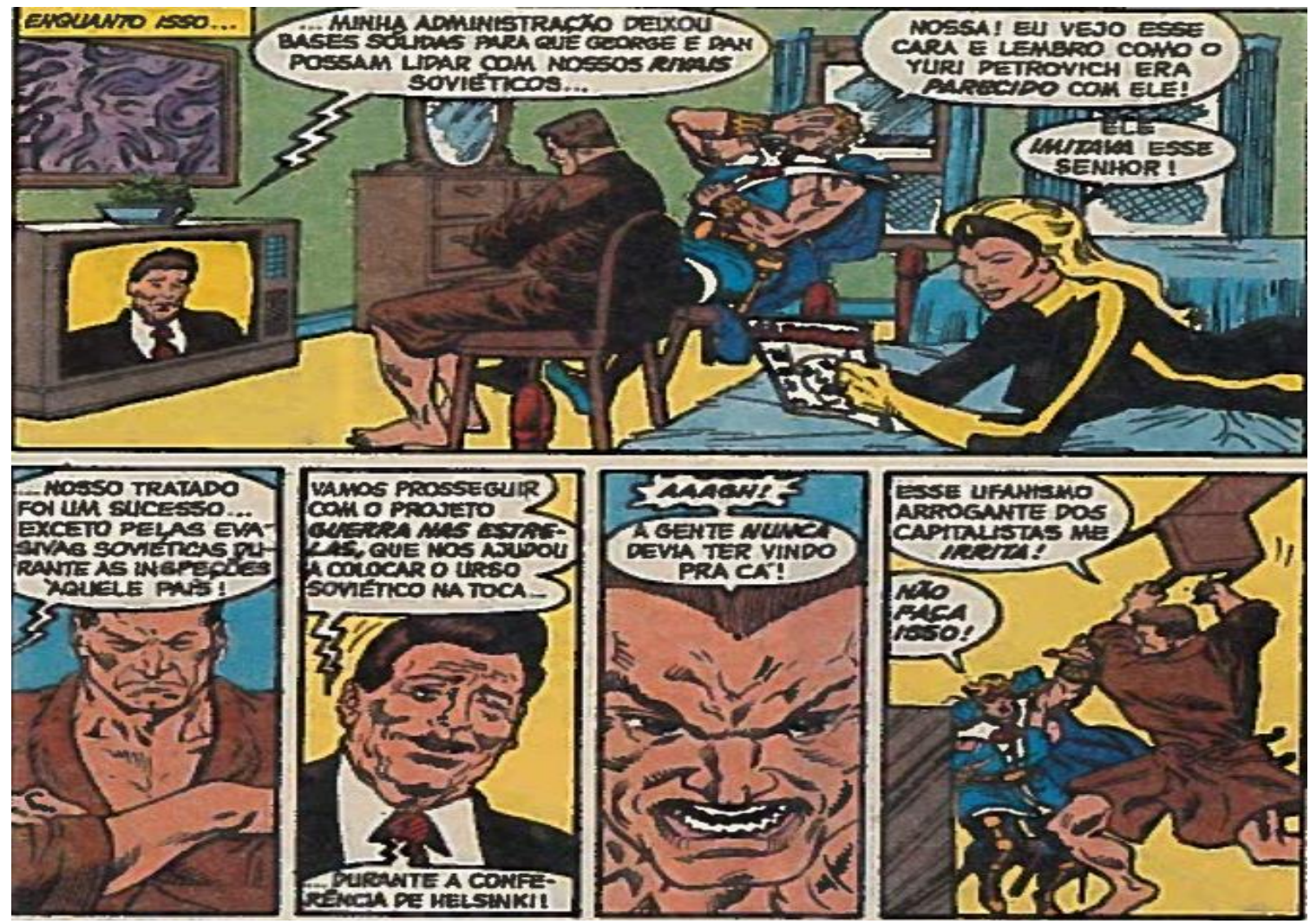

Como já ressaltamos, essa HQ foi publicada originalmente no contexto histórico da Guerra Fria, ou mais especificamente, no período que ficou conhecido como a "Nova Guerra Fria”, que se estende de 1981 a 1991. Esse período é marcado pela emergência de Ronald Reagan, membro do Partido Republicano, como presidente dos Estados Unidos. Reagan foi eleito em 1981 e depois reeleito, permanecendo no cargo até 1989 (data da publicação desta HQ nos EUA). Nesse momento, ele sugere que sua administração estava chegando ao fim e que o próximo presidente, George Bush, também do partido Republicano, teria as condições de lidar com os "rivais soviéticos".

A eleição de Reagan representou o coroamento das forças da direita nos EUA, justificado pelo medo dos norte-americanos de que revoluções sociais ou nacionalistas, como as ocorridas no Terceiro Mundo durante a década de 1970, além da Revolução Iraniana, pudessem exercer um "efeito dominó" nas partes periféricas do globo.

Segundo o historiador Paulo F. Vizentini, na "Era Reagan" a estratégia "era oposta a qualquer multilaterização das relações internacionais e contrária ao diálogo Norte-Sul, buscando restaurar uma estrita bipolaridade com vantagem estratégica para os EUA" (2005, p. 222). Este clima de tensão é retratado na HQ quando o presidente Reagan aparece na televisão 
exaltando o projeto Guerra nas Estrelas - projeto esse que previa a construção de satélites equipados com lasers para interceptar mísseis soviéticos ${ }^{12}$ :

Minha administração deixou bases sólidas para que George e Dan possam lidar com nossos rivais soviéticos...Nosso tratado foi um sucesso...exceto pelas evasivas soviéticas durante as inspeções àquele país. Vamos prosseguir com o projeto Guerra nas Estrelas, que nos ajudou a colocar o Urso Soviético na toca durante a conferência de Helsinki.

A conferência de Helsinki, ocorrida em 3 de julho de 1973 na cidade de Hensínquia, capital da Finlândia, foi assinada por EUA e URSS, sendo ela responsável por delimitar as fronteiras entre o Leste Europeu e a Europa Central, contendo um suposto expansionismo soviético. Ela é lembrada nesta HQ como um fato positivo na política externa estadunidense ${ }^{13}$.

O interessante de notarmos nesta passagem é a reação do personagem Mikhail Ursus diante da fala do presidente dos EUA, pois ao ouvi-la, ele imediatamente responde: "Aaargh! A gente nunca devia ter vindo pra cá! Esse ufanismo arrogante dos capitalistas me irrita!", chegando a quase arremessar uma cadeira no aparelho de televisão, sendo contido por Vanguard, seu parceiro de equipe. Assim, mais uma vez podemos notar como o clima ideológica da Guerra Fria é representado na HQ, e isso tanto na fala do presidente dos EUA quanto no gesto do personagem Mikhail Ursus, que inclusive intitula os norte-americanos ufanistas arrogantes!

O final desta primeira parte ocorre com o retorno do Capitão América aos aposentos dos SSS. Mas algo inusitado ocorre, o Capitão diz aos membros desta equipe que o estado norte-americano pediu a ele para realizar um teste com os poderes dos SSS para "ver se são quem dizem ser”. Neste momento, há uma grande desconfiança por parte de Vanguard, que contra-argumenta lembrando ao Capitão que ele já teria presenciado uma cena de ação quando da confusão entre eles e o novato grupo de super-heróis. Mesmo assim, o Capitão América insiste e acaba por conduzir os SSS até o pavilhão de treinamento, onde chegam e encontram mais três membros dos Vingadores (Visão, Homem de Ferro e Thor).

\footnotetext{
${ }^{12} \mathrm{O}$ projeto Guerra nas Estrelas - oficialmente chamado de SDI, que era uma sigla em inglês para Iniciativa de Defesa Estratégica - nunca foi de fato concretizado e acabou por ser arquivado no ano de 1993.

${ }^{13}$ Entretanto, o trunfo do qual se vangloria o presidente dos EUA para as negociações nesta passagem da HQ, o projeto Guerra nas Estrelas, ainda não existia na época desta conferência. Assim, há um erro cronológico, pois a Conferência de Helsinki data de 1973 enquanto o projeto Guerra nas Estrelas foi lançado pelo presidente Ronald Reagan em 1983.
} 
Neste momento, o Capitão América avisa que haverá apenas uma simulação de combate e solicita para os SSS demonstrarem seus poderes. Entretanto, o que apresentava-se como uma simulação toma a forma de um verdadeiro massacre, sendo os SSS quase mortos pelos Vingadores.

Entretanto, e aqui entra o poder da imaginação típico das histórias em quadrinhos, a verdade é revelada: não se tratava dos Vingadores (nem, naquele momento, do próprio Capitão América), mas sim de um outro grupo de super-seres oriundos da URSS, chamado Sovietes Supremos, e que haviam ficado momentaneamente com a aparência dos Vingadores para enganar os SSS. Essa aparência enganosa seria fruto dos poderes de uma heroína russa chamada Fantasia.

A razão do confronto era que os SSS foram tidos como "traidores da pátria" pelo governo da URSS, pois fugiram do país e pediram “asilo político" nos EUA. Em função dessa traição, o governo russo enviou secretamente um outro grupo para aniquilar seus desertores.

Duas horas mais tarde, o verdadeiro Capitão América retorna de sua missão e, ao chegar ao quartel dos Vingadores, depara-se com os três integrantes do SSS gravemente feridos. A finalização desta primeira parte da história ocorre com o Capitão América, sem saber o que aconteceu, solicitando ajuda aos médicos e enfermeiros do local para tentar salvar da morte os Super Soldados Soviéticos.

\section{SEGUNDA PARTE: “O GRANDE URSO”}

O título dessa segunda parte da história, uma continuação de "Asilo", faz referência não apenas ao personagem do grupo que se transforma em urso, mas também ao fato do urso ser um dos símbolos da URSS. A história chamada "O Grande Urso" começa onde "Asilo" termina, com os integrantes dos SSS sendo atendidos por médicos e enfermeiros no quartel dos Vingadores.

Em função do ocorrido, o Capitão América desloca-se de avião até a URSS para evitar que o episódio tome a dimensão de um incidente internacional. Ao aterrissar em Moscou, ele é recepcionado por Boris Prokofiev, que se apresenta como Ministro das Relações Exteriores. Em seguida, o Capitão solicita uma audiência com os líderes políticos daquele país, quando profere as seguintes palavras: 
Estimados líderes da União das Repúblicas Socialistas Soviéticas. Venho a vocês como cidadão americano e como embaixador dos Vingadores, um grupo de super humanos que busca manter a paz no mundo. É o meu desejo sincero estabelecer meios concretos pelos quais os Vingadores possam ajudar o povo desta nação em situações de emergência, como fazemos em outras partes do mundo!

Ao final deste discurso, o Capitão América é aplaudido pelos líderes soviéticos, sendo exibido em destaque nos quadrinhos um personagem que é a representação do presidente Mikhail Gorbachev. Interpretamos essa passagem como um modo do roteirista desta HQ explicitar as boas intenções do herói símbolo dos EUA em manter relações com o "inimigo", buscando promover a paz e ajudar o povo daquela nação.

Após este discurso, o Capitão América é levado a um quarto de hotel. Neste momento da HQ, começa a aparecer uma projeção um tanto quanto fantasmagórica de um grande monstro em formato de energia negra. Sobre este fato, iremos comentar no final do artigo. No momento, para nossos interesses, cabe analisar o encontro que ocorre, na manhã seguinte, entre o Capitão América e sua versão soviética, chamado Guardião Vermelho. O encontro entre os dois é reproduzido na imagem a seguir:

Figura 5 - Encontro entre o Capitão América e o Guardião Vermelho

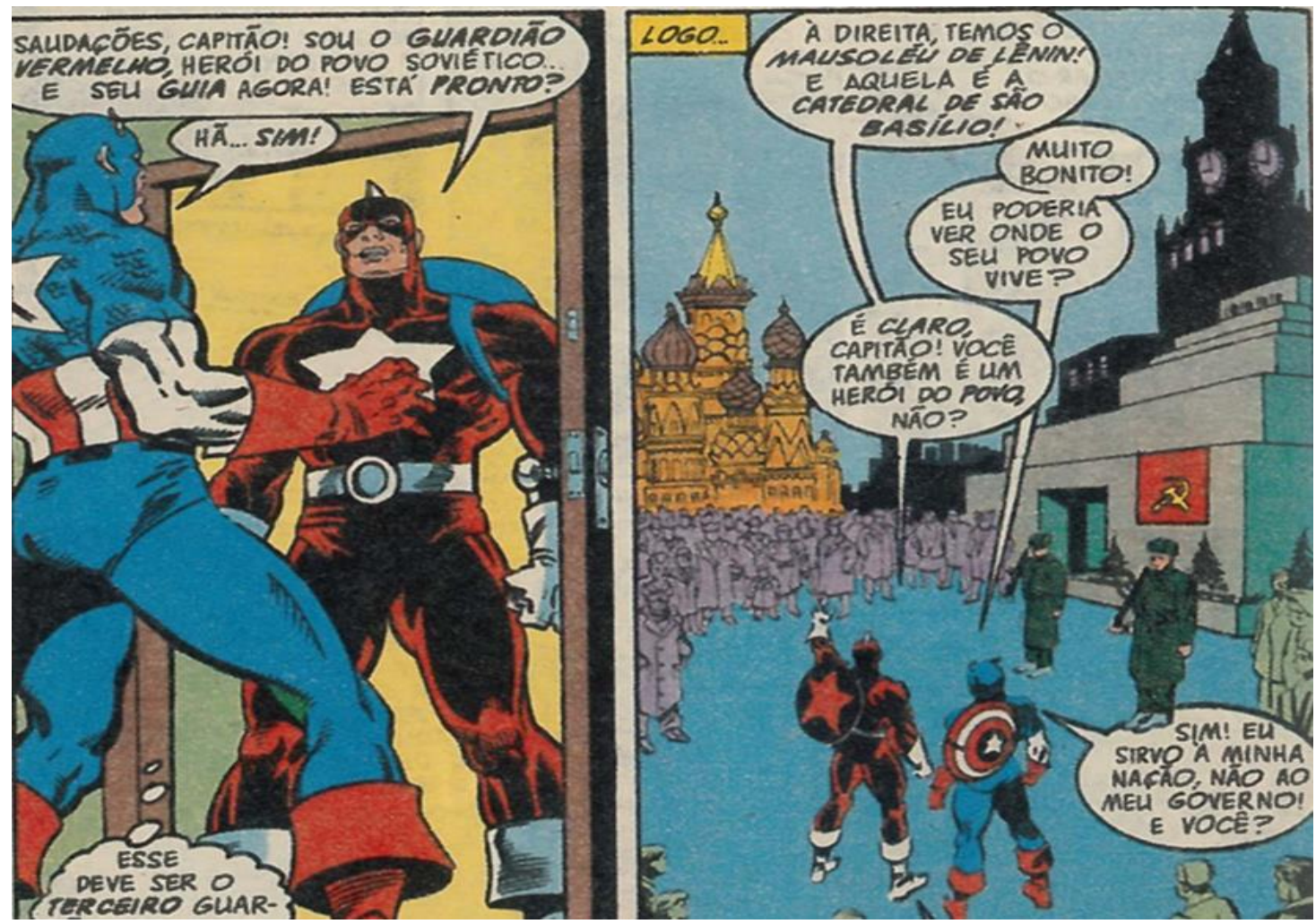


Antes da formação dos Super Soldados Soviéticos, a editora Marvel, em agosto de 1967, numa revista em quadrinhos dos "Vingadores", trouxe a público um herói soviético chamado "Guardião Vermelho". Fora de sua identidade secreta, ele era conhecido como Alexi Shostakov, pois era um dos pilotos de teste mais aclamados da União Soviética, cujo heroísmo chamou a atenção da $\mathrm{KGB}$, que o recrutou para um projeto secreto, cujo objetivo era desenvolver um ser tão perfeito quanto o Capitão América. Ao final, "o projeto foi um sucesso e Shostakov recebeu a identidade e o uniforme de Guardião Vermelho"14.

Nesta HQ do Capitão América, visualizamos o encontro entre ambos. Interessante notarmos que a Marvel reproduziu no Guardião Vermelho praticamente a mesma indumentária e o mesmo artefato (um escudo) usado pelo Capitão América, modificando apenas as cores para o vermelho. Deste modo, com a criação deste super-herói, ela identificava com precisão os dois principais agentes da Guerra Fria, os EUA e a URSS, sendo que cada uma das superpotências tinha seus heróis símbolos praticamente iguais (apenas com cores diferentes).

Ainda na imagem reproduzida (figura 5), observamos o Guardião Vermelho apresentando sua cidade para o Capitão. Ele o leva até a Praça Vermelha, o coração de Moscou, lugar que reúne os elementos arquitetônicos mais significativos da cidade. Eles aparecem ao lado do "Mausoléu de Lenin" e próximos a "Catedral de São Basílio". Esta catedral, assim como o Mausoléu de Lenin, são de fato dois dos símbolos mais famosos da Rússia, sendo a Catedral erguida em 1561 a mando do czar Ivan, o Terrível.

No lado direito desta imagem, podemos conferir a presença da bandeira vermelha, com a foice e o martelo, além de dois soldados russos, que faziam a proteção do túmulo de Lenin. A conversa entre os dois Capitães é emblemática, pois enquanto o Capitão América afirma servir a sua nação, o Guardião Vermelho responde que, no seu país, o povo e o governo são a mesma coisa.

O passeio dos dois super-heróis continua pela cidade. Por onde passa, o Guardião Vermelho é reconhecido pelo seu povo, demonstrando ser bastante popular em seu país. Interessante notarmos que, numa das cenas desenhadas, aparece a fala de um cidadão soviético que, ao enxergar os dois heróis juntos e compará-los, diz: "O nosso herói deixa o americano no chinelo, hein?".

\footnotetext{
14 http://www.guiadosquadrinhos.com/personagem/guardiao-vermelho-ii-(alexi-shostakov)/1528, acesso em:
} $29 / 03 / 2018$ 
No final desta HQ, tanto o Capitão América quanto o Guardião Vermelho se unem em Moscou para enfrentar um gigante monstro formado de energia negra. Em meio ao combate, surge também o grupo dos Sovietes Supremes (o mesmo que, disfarçado de Vingadores, havia derrotado os desertores dos SSS em Nova Iorque). Neste momento, o Capitão América se dá conta que havia um outro grupo de super-seres na URSS para além dos SSS, o que o deixa confuso e o faz pensar na hipótese deste grupo ter atacado os SSS nos EUA.

A HQ chega ao fim sem que o Capitão América encontre sua resposta. Na última cena, ele aparece refletindo sobre a confusa história na qual se viu envolvido, e pondera: "Ainda não sei se o ataque a eles (SSS) foi ordenado pelo Comitê de Poderes Especiais (da URSS) ou não! De qualquer forma, preciso reforçar a segurança pra impedir outro ataque como esse”. E ainda complementa: "Becos sem saída...perguntas sem respostas....é como as coisas tem sido ultimamente!".

Para o Capitão América, imerso na confusão dos fatos, não havia certezas, mas hipóteses e dúvidas. Por outro lado, para o leitor atento da HQ, havia clareza de que o ataque ao SSS havia sido tramado pelo próprio governo da URSS, que enviou uma outra equipe de super-seres para assassiná-los, buscando ainda imputar a culpa pelo ato nos próprios Vingadores. Neste episódio, não há como não lembrar das perseguições efetuadas por Stalin aos seus opositores, em especial, a Trotsky, morto por um agente secreto enquanto se encontrava em seu exilio no México.

A história "Asilo" e "O Grande Urso" reforça a ideia de que o governo da URSS perseguia seus opositores, o que fazia o país estar distante da liberdade e do mundo-livre. A URSS, nesta versão dos quadrinhos, seria o exato oposto dos EUA, pois enquanto este era representado como a terra da liberdade e da democracia, a URSS figurava como a terra de um governo autoritário e ardiloso, que punia até mesmo seus próprios super-heróis quando esses não concordavam em realizar o trabalho "sujo" que seus governantes encomendavam.

\section{CONSIDERAÇÕES FINAIS}

As Histórias em Quadrinhos (HQs) desenvolveram-se ao longo do século XX em íntima relação com a cultura de massas e, sobretudo, com a ampliação da juventude como uma categoria social. Deste modo, elas fazem parte de um amplo leque de artefatos produzidos pela indústria cultural norte-americana ao longo do século passado. Nela, assim como na televisão, nos filmes, nos desenhos animados ou nas revistas ilustradas, existem 
representações que são veiculadas, opiniões emitidas e narrativas que ajudam a produzir o imaginário social de um período.

Durante a Guerra Fria (ou desde a Guerra Fria), a Rússia foi transformada em uma rival do Ocidente, chegando mesmo a ser demonizada como uma eterna expansionista (BERTONHA, 2011, p. 165). Nesse sentido, a análise que empreendemos indica que o clima de tensão deste período também foi transportado para as HQs, sendo possível identificar uma série de elementos que nos falam diretamente sobre os significados dessa disputa ideológica que marcou fortemente o século XX.

Dentre os elementos analisados, destacamos os seguintes: 1) Pedido de "Asilo Político" dos Super Soldados Soviéticos ao Capitão América, o que ajuda a fortalecer o imaginário social dos Estados Unidos como a terra das liberdades democráticas em oposição a URSS como um Estado Totalitário; 2) Menção aos "trabalhos sujos" que os integrantes do grupo dos Super Soldados Soviéticos eram obrigados a realizar a pedido do governo socialista. Tal fato indica perseguições aos opositores do regime e mesmo faz alusão aos gulags; 3) Em solo americano, um aspirante a Vingador chama Vanguard de "Vermelho nojento", o que nos indica o clima de tensão da Guerra Fria e o modo como o socialismo era partilhado e interpretado na cultura estadunidense; 4) As constantes desconfianças do major Mikhail Ursus com a hospitalidade do Capitão América (clima de não confiança entre os dois países); 5) O pronunciamento do ex-presidente Ronald Reagan e a menção ao projeto Guerra nas Estrelas, seguido da irritação do Mikhail Ursus; 6) A existência de uma versão comunista do Capitão América, chamado Guardião Vermelho, e a forma como esse apresentou os símbolos de seu país para aquele, com destaque para o "Mausoléu de Lenin", o principal líder da revolução bolchevique de 1917; 7) A perseguição promovida pela URSS aos Super Soldados Soviéticos, tido por ela como um grupo de super-heróis desertores.

Por fim, consideramos esta HQ como um espaço de veiculação do imaginário social do período da Guerra Fria, sendo ela uma produção estética e discursiva que traz elementos importantes do embate ideológico próprio deste contexto histórico. Nela, encontram-se presentes todo um conjunto de manifestações que dizem respeito ao modo como a URSS vinha se estabelecendo no imaginário e na cultura política produzida e partilhada pela indústria cultural estadunidense. Assim, a URSS seria um local contrário as liberdades democráticas e de onde até mesmo seus super-heróis precisavam fugir para não cometerem os "trabalhos sujos" encomendados pelos líderes socialistas. 


\section{REFERÊNCIAS BIBLIOGRÁFICAS}

BERNARDO, Thiago Monteiro. Histórias em quadrinhos e política. In: SILVA, Francisco (org.). Enciclopédia de guerras e revoluções: vol. II: 1919 - 1945: a época dos fascismos, das ditaduras e da Segunda Guerra Mundial (1939 - 1945). Rio de Janeiro: Elsevier, 2015, p. 115 -119 .

BERTONHA, João Fábio. Rússia: ascensão e queda de um império: uma história geopolítica e militar da Rússia, dos czares ao século XXI. Curitiba: Juará, 2011.

HARUMI, Patrícia. O fantástico mundo dos super-heróis. São Paulo: Editora Pixel, 2016.

HOBSBAWM, Eric. Era dos Extremos: o breve século XX: 1914 - 1991. São Paulo: Companhia das Letras, 1995.

HOWE, Sean. Marvel Comics: a história secreta. São Paulo: LeYa, 2013.

PARADA, Maurício. Formação do mundo contemporâneo: o século estilhaçado. Vozes: Rio de Janeiro: Editora PUC, 2014.

VAZQUEZ, Laura; PIRES, Conceição. Percursos teóricos e metodológicos dos estudos sobre HQs na Argentina e Brasil. In: RODRIGUES, Rogério Rosa (org.). Possibilidades de pesquisa em História. São Paulo: Contexto, 2017, p. 137 - 170.

VIANA, Nildo. Histórias em quadrinhos e métodos de análise. In: Revista Temporis [ação], v. 16, n. 2, 2016, p. $40-60$.

VALIM, Alexandre Busko. Cinema e Guerra Fria: entre Hollywood e Moscou. In: TEIXEIRA DA SILVA, Francisco Carlos; LEÃO, Karl Schurster Sousa; LAPSKY, Igor (Org.). O cinema vai à guerra. Rio de Janeiro: Elsevier, 2015, p. 179 - 191.

VIZENTINI, Paulo Fagundes. A Guerra Fria. In: REIS FILHO, Daniel Aarão; FERREIRA, Jorge; ZENHA, Celeste (Org.). O século XX. Rio de Janeiro: Civilização Brasileira, 2005, p. $195-225$. 